\title{
WHEN IT RAINS WHILE THE SUN IS SHINING: SCHOOL CLIMATE AS AN ECHO OF THE (FUTURE) SOCIAL CLIMATE
}

\author{
Diana Dias ${ }^{1,2}, \&$ Raquel Barroso ${ }^{1}$ \\ ${ }^{I}$ CIPES - Center for Research in Higher Education Policies (Portugal) \\ ${ }^{2}$ Universidade Europeia (Portugal)
}

\begin{abstract}
Considering that a society is a 'particular grouping of humanity with shared customs, laws etc.', school meets all these criteria and, given that, it may be called a society within a society, a miniature society that exists within a larger society. Schools provide a social context for a broader and more complex social world. Hence, school is more than a context for academic learning, it is also a place where children learn to build positive social relationships, gain independence and develop emotionally, behaviourally, and cognitively. School attendance involves navigating peer interaction, solving social problems, developing the socioemotional and relational skills essential to build and maintain relationships. What happens in the social life of children is central to the sense of comfort and safety in school and to participation in school tasks and their school results. The school climate involves the quality and consistency of interpersonal relationships, the sense of belonging to the school community and the perceived safety that the School conveys and seems to be reflected in the socio-emotional adjustment and mental health of children and young people. In addition, school and behavioural outcomes also appear to be associated with the school climate. There has been a significant and rising interest in improving the school climate in recent years. This is due to the following three factors. First, there is a growing number of empirical researches that support the notion that context is important. Second, there is an increasing perception that a better school climate supports the effective prevention of violence in general. Third, there is an upward interest in the promotion of transversal skills such as moral values, socio-emotional skills, mental health promotion efforts, and the promotion of citizenship through community engagement. This growing interest in research on the school climate has also been seen at the political level. This is considered an essential aspect in the development of programs to promote socio-emotional skills and to prevent behaviour problems. It is intended that school climate and safety can be non-academic indicators for classifying schools. The present study aims to analyse the school leaders' perceptions about the school climate. It is intended to describe their conceptualizations about the subject, as well as their reflections on the utility and implications of the concept. Through content analysis it will be possible to reflect on the trends, challenges and implications of this concept, presenting the implications for practice and for research.
\end{abstract}

Keywords: School climate, primary school, education, school success school leaders.

\section{Introduction}

The importance of school climate was already recognized over 100 years ago, when Arthur Perry published the Management of a City School (1908). Perry recognized the need to provide students with a quality learning environment. However, school climate didn't take part in the field of empirical research until the early 1960s, when an instrument for assessing the organizational climate was developed. It was at that time that the effects of the school organizational climate on learning and students' development began to be systematically studied. Over the past few decades, researchers and educators have realized that the initial conceptualization of school climate was overly simplistic, hence recognizing school climate as a multidimensional construct (Wang \& Degol, 2016).

School climate brings together the social, emotional and physical features of the school community (Voight \& Hanson, 2017). According to Cohen et al. (2009), the school climate is the "life's school quality and character," which includes "norms, values, and expectations that support people in feeling socially, emotionally, and physically safe" (p. 182). Metaphorically it is the heart and soul of the school (Bear et al., 2016). 
All definitions of school climate include references to the importance of positive interpersonal relationships and a sense of belonging. Many even include the importance of students and professionals feeling safe in school (Bear et al., 2016).

It is, therefore, currently agreed that the school climate is multidimensional. The inclusion of multiple domains enriches research in this field and increases the likelihood of significant change through school reform initiatives that focus on multiple pathways to student success. The school climate can be a potentially promising target for intervention. More and more empirical research on school-wide interventions supports the premise that changing the social processes of the school climate will produce better outcomes for students in various fields.

Although there is agreement on the complexity of this construct, the authors greatly differ in the dimensions they include in the school climate. Wang and Degol (2016) elaborated a literature review, identifying and categorizing the multiple dimensions described in the literature into 4 domains, corresponding to 13 dimensions (see figure 1).

Figure 1. School's Climate Dimensions (Wang \& Degol, 2016).

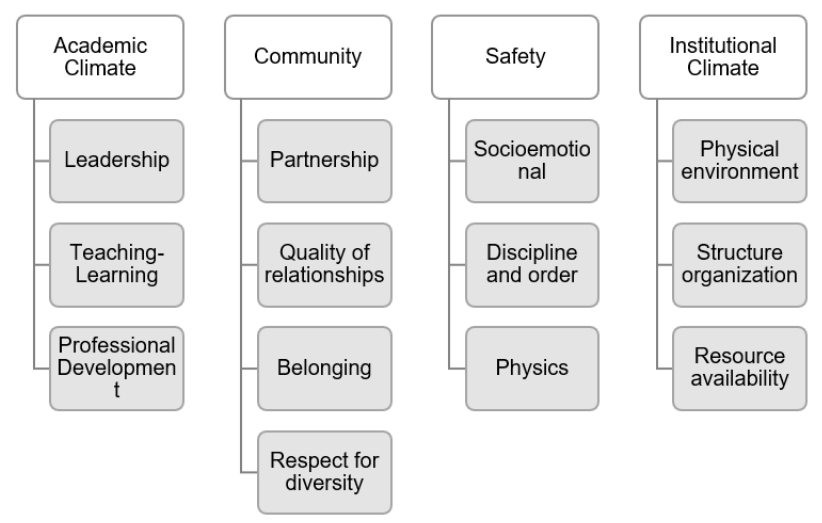

The multidimensionality of school climate is, however, represented in the literature, which defines the school climate in four ways: academic, community, security and institutional climate. These four broad categories provide one of the most comprehensive conceptions of school climate quality. The academic climate focuses on the overall quality of the academic atmosphere, including curricula, teaching-learning process, teacher training and their professional development. The community emphasizes the quality of interpersonal relationships within the school. Safety represents the degree of physical and emotional security provided by the school, as well as the presence of effective, consistent and fair disciplinary practices. Finally, the institutional environment reflects the organizational or structural characteristics of the school environment. Collectively, these four dimensions encompass almost all features of the school environment that affect students' cognitive, behavioural, and psychological development (Wang \& Degol, 2016).

School climate has been shown to be predictive of students' academic, behavioural and psychological outcomes (Wang \& Degol, 2016).

A broad set of studies has shown that a more positive school climate is associated with greater academic success. The most consistent results demonstrate the importance of the academic and community dimensions in promoting school success. Schools that set high academic standards, have effective leadership, emphasize learning goal orientation and have students who demonstrate higher academic performance. Similarly, community characteristics such as close teacher-student relationships, regular communication between parents and schools, and valuing diversity evoke an academic environment that is conducive to learning and promotes motivation and school success among students. Institutional and safety factors, on the other hand, appear to be less consistently associated with academic achievement, with effects that often disappear when other school climate factors are controlled (Wang \& Degol, 2016).

Regarding the academic climate, the quality of an academic environment has been widely documented as an important predictor of student achievement in primary and secondary school samples (Lee, Smith, Perry \& Smylei, 1999). The best performing schools tend to emphasize the importance of commitment to high academic standards and are characterized by the effective leadership of teachers and leaders. On the other hand, schools characterized by high quality interpersonal relationships, communication, cohesion and feelings of belonging to the school community are better able to support students' psychological needs and promote optimal development in academic fields. Positive relationships 
with teachers and between students have been shown to have a positive relationship with standardized test scores (Esposito, 1999) and students' motivation to learn (Patrick, Ryan \& Koplan, 2007).

Research has also shown the importance of the school climate in reducing student behaviour problems. The school climate dimensions related to community resources and safety perception are those that seem to be most associated with students' behavioural differences (Wang \& Degol, 2016).

The results of several studies have shown that there is a connection between the quality of interpersonal relationships in the school environment and the experiences of bullying, aggression and delinquency. Students' perceptions of cohesion in the school community and their sense of belonging to this community are associated with a lower risk of victimization and involvement in bullying (Zaykowski \& Gunter, 2012) and less violent behaviour. Similarly, students are more willing to intervene or report risk behaviours when they realize that the school environment has a strong sense of solidarity and community belonging (Syvertsen, Flanagan, \& Stout, 2009).

Similarly, quality peer relationships have been associated with a reduction in aggression, victimization, and behaviour problems (Elsaesser, Gorman-Smith, \& Henry, 2013). Pupils attending schools where their peers are attentive or helpful, have experienced better adaptation to the school. This favourable adaptation also predicted better health and fewer psychosomatic symptoms (Hendron \& Kearney, 2016).

Research has shown that community characteristics that emphasize school belonging, respect for students' opinions and social supportive relationships are essential determinants of psychological functioning. For example, in a study with a large transnational sample, adolescents in schools characterized by a more distant social environment (for example, students who reported not feeling they belonged to school) reported worse emotional adjustment results when compared to adolescents in schools characterized by a higher relational quality (Freeman et al., 2009). Positive interpersonal relationships have been consistently linked to more positive adjustment and lower prevalence of psychopathology (Way, Reddy, \& Rhodes, 2007). In fact, more positive interpersonal relationships between students and also between students and teachers, as well as greater parental involvement in school, have been associated with greater life satisfaction (Suldo, Thalju-Raitano, Hasemeyer, Gelley, \& Hoy, 2013), better coping strategies, higher self-esteem and optimistic attitudes toward school (Ruus et al., 2007). These results demonstrate that the quality of interpersonal relationships within the school is one of the most robust predictors of psychological adjustment (Wang \& Degol, 2016).

In terms of safety's perception, a recent meta-analysis of social and emotional learning interventions, aimed at improving school safety and reducing problem behaviours, found evidence of the impact of these interventions on social and emotional skills, on the attitudes towards oneself and school and positive social behaviours (Durlak, Wessberg, Dymnicki, Taylor, \& Schellinger, 2011). It was also possible to observe a decrease in behavioural problems and emotional distress when compared with the control group, giving empirical support to the importance of improving school safety in promoting psychological adjustment. In the same line of though, students' perceptions of fairness of classroom rules, discipline, and overall school safety are negatively associated with psychological distress, including loneliness, anxiety, and depression (Hendron \& Kearney, 2016), as well as a decrease in internalization and externalization symptoms (Suldo, McMahan, Chappel, \& Loker, 2012). A study led by the University of Tallinn on dropout prevention has shown that the school climate perceived by students, especially the school's value system and teachers' attitudes towards students influences the students' upbeat acceptance about life, its physiological well-being and consequently its academic success (Ruus et al., 2007). These results suggest that the school climate may have moderating effects on student well-being (Voight \& Hanson, 2017). Considering climate effect relevance, this study aims to analyse the perceptions of school leaders about the school climate. It is intended to describe their conceptualizations about the subject, as well as their reflections on the utility and implications of the concept.

\section{Methodology}

\subsection{Participants}

10 leaders of 10 primary school partook the present study: $6(60 \%)$ female and $4(40 \%)$ male, aged between 38 and 61 years $(M=47.90, S D=7.80)$. All primary school leaders had a bachelor's degree and belonged to school staff, working as teachers on average for 22.70 years $(S D=7.53$, Min $=14$, Max $=38)$. They have worked in the current school, on average, 17.20 years $(S D=6.53$, Min $=9, \operatorname{Max}=31)$ and belonged to the school board, on average, for 14.60 years $(S D=7.55$, Min $=2$, Max $=30)$. Most of the primary school leaders $(60 \%, n=6)$ belonged to the Porto district and $40 \%(n=4)$ to the Lisbon district. 


\subsection{Instruments}

Sociodemographic data was collected by completing an individual identification form constructed within the scope of this research. Participants' perceptions of school climate were assessed by a questionnaire constructed also within the scope of the present study, in which participants answered on a 5 -point likert scale where 1 meant very bad and 5 very good.

\subsection{Procedures}

The present study obtained a positive opinion from the Ethics Committee of the Universities to which the authors affiliate and from the Directorate General for Education to carry out research in school context.

A representative sample of 3rd year students from the primary school was selected to take part in the study and the National Confederation of Parents' Associations, the National Association of Directors of School Districts and Public Schools and the National Association of Teachers were established as research partners. After the first contact made by one of the research partners to the selected school districts, study aims were explained. Whenever a positive response was obtained, a second contact was made to all school districts by the researchers for a more detailed explanation of the aims of the study, sending an informed consent and scheduling of the data collections.

All participants and school districts filled in an informed agreement.

Data was analysed using IBM SPSS, version 25.0 for Windows.

\section{Results and discussion}

\subsection{School's climate characterization}

Table 1 presents the descriptive measures of school climate.

Table 1. Descriptive measures of school climate.

\begin{tabular}{lcccc}
\hline & Min & Max & Mean & SD \\
\hline School climate among students & 4 & 5 & 4.50 & 0.53 \\
School climate among teachers & 4 & 5 & 4.30 & 0.48 \\
School climate between students and teachers & 4 & 5 & 4.40 & 0.52 \\
School climate between teachers and school management & 4 & 5 & 4.60 & 0.52 \\
School climate between parents and teachers & 4 & 5 & 4.50 & 0.53 \\
School climate between parents and school management & 4 & 5 & 4.60 & 0.52 \\
\hline
\end{tabular}

The results show that the participants consider that there is an extremely positive school climate in their schools, in several features, considering that the averages obtained were above 4 and the answers ranged from 4 to 5 . Bearing in mind the number of participants and the proximity of averages obtained, no tests were performed to understand if there were differences in averages associated with different aspects of school climate. However, it would be important to increase the number of participants, in order to understand if the response tendency remains with the increase of participants and clarify which characteristics the school leaders consider to contribute to better and worse school climate. Only this clarification could allow to intervene preventively or to remedy such dimensions that they consider to be more negative, and fostering the ones which they recognized as promoters of the well-being of all students and all educational agents.

\section{Conclusions}

The present study aimed to characterize the school climate according to the perception of primary school principals, who was been consulted to evaluate their perceptions and opinions. To do that, it was used a self-answer questionnaire built in the scope of the present research.

In fact, all participants consider that there is a positive school climate in their schools, approaching the answers obtained to the maximum values. They also found that this positive school climate is transverse to various dimensions of this construct, especially the school climate between school management and teachers and parents. Although the number of school principals to be relatively small, it cannot be overlooked that they seem to see themselves as the main promoters of a positive school climate. In fact, the highest evaluations are observed precisely when the school climate is assessed among the principals themselves and other educational agents. On the other hand, and although the evaluations are still high, it is noted that the school climate among teachers and between them and students are the aspects of the school climate with the lowest evaluations, in the school principals' opinion. 
However, in order to allow the generalization of results and to define intervention strategies that promote a better school climate, it would be necessary to increase the number of the sample that would allow more robust statistical analysis.

It would be equally important to understand what variables related to school, students and their families and teachers contribute to the development of a positive school climate.

In fact, research studies focus in the school climate are particularly interesting and needed because it is believed that school climate could be an echo of the (future) social climate.

\section{References}

Bear, G., Yang, C., Harris, A., Mantz, L., Hearn, S., \& Boyer, D. (2016). Technical Manual for Delaware School Survey: Scales of School Climate, Bullying Victimization, Student Engagement, and Positive, Punitive, and Social Emotional Learning Techniques.

Cohen, J., McCabe, E., \& Michelli, N. (2009). School Climate: Research, Policy, Practice, and Teacher Education, Teachers College Record, 111(1), 180 - 213.

Durlak, J., Weissberg, R., Dymnicki, A.,Taylor, A., \& Schellinger, K. (2011). The Impact of Enhancing Students' Social and Emotional Learning: A Meta-Analysis of School-Based Universal Interventions, Child Development, 82, 1, 405 - 432.

Elsaesser, C., Gorman-Smith, D., \& Henry D. (2013). The role of the school environment in relational aggression and victimization, Journal of Youth and Adolescence, 42, 2, 235 - 249. doi: 10.1007/s10964-012-9839-7

Esposito, C. (1999). Learning in urban blight: School climate and its effect on the school performance of urban, minority, low-income children, School Psychology Review, 28, 3, 365 - 377.

Freeman, J., Samdal, S., Klinger, D., Dur, W., Griebler, R., Currie, D., \& Rasmussen, M. (2009). The relationship of schools to emotional health and bullying, International Journal of Public Health, 54, 251 - 259.

Hendron, M., \& Kearney, C. (2012). School climate and student absenteeism and internalizing and externalizing behavioral problems, Children and Schools, 38, 2, 109 - 116. doi: $10.1093 / \mathrm{cs} / \mathrm{cdw} 009$

Lee, V. E., Smith, J. B., Perry, T. E., \& Smylie, M. A. (1999). Social support, academic press, and student achievement: A view from the middle grades in Chicago.

Patrick, H., Ryan, A., \& Kapaln, A. (2007). Early adolescents' perceptions of the classroom social environment, motivational beliefs, and engagement, Journal of Educational Psychology, 99, $83-98$.

Ruus, V., Veisson, M., Leino, M, Ots, L., Pallas, L., Sarv, E., \& Veisson, A. (2007). Students' well-being, coping, academic success, and school climate, Social Behavior and Personality: An International Journal, 35, 919 - 936.

Suldo, S., McMahan, M., Chappel, A., \& Loker, T. (2012). Relationships between perceived school climate and adolescent mental health across genders, School Mental Health, 4, 2, 69 - 80. doi: 10.1007/s12310-012-9073-1

Suldo, S., Thalji-Raitano, A., Hasemeyer, M., Gelley, C., \& Hoy, B. (2013). Understanding middle school students' life satisfaction: does school climate matter?, Applied Research in Quality of Life, 8, 169 - 182.

Syvertsen, A., Flanagan, C., \& Stout, M. (2009). Code of silence: students' perceptions of school climate and willingness to intervene in a peer's dangerous plan, Journal of Educational Psychology, 101, $219-232$.

Voight, A., \& Hanson, T. (2017). How are middle school climate and academic performance related across schools and over time? (Report - REL 2017-212). Department of Education, Institute of Education Sciences, National Center for Education Evaluation and Regional Assistance, Regional Educational Laboratory West. Washington, DC: U.S.

Wang, M., \& Degol, J. (2016). School Climate: A Review of the Construct, Measurement, and Impact on Student Outcomes, Educational Psychology Review, 28, 2, 315 - 352. doi: 10.1007/s10648-0159319-1

Way, N., Reddy, R., \& Rhodes, J. (2007). Students' perceptions of school climate during the middle school years: associations with trajectories of psychological and behavioral adjustment, American Journal of Community Psychology, 4, 194 - 213.

Zaykowski, H., \& Gunter, W. (2012). Youth victimization: School climate or deviant lifestyles?: Erratum, Journal of Interpersonal Violence, 27, 8, 1625 - 1627. doi: 10.1177/0886260512446897 